\title{
EL MARXISMO DES-COLONIZADO COMO DETRACCIÓN A LA CRÍTICA DE POPPER AL HISTORICISMO
}

\author{
DANIEL ALBERTO SICERONE ${ }^{1}$ \\ Universidad del Zulia. \\ Código Postal 4004, Maracaibo, Venezuela. \\ daniel.sicerone@hotmail.com
}

\section{RESUMEN}

Se persigue abordar la crítica de Popper al historicismo, realizada desde su perspectiva sobre la filosofía de la ciencia, concibiendo la relación entre la racionalidad tecno científica y la racionalidad instrumental en la filosofía popperiana. Metodológicamente, se reflexiona acerca de la hermenéutica que hiciera Popper del marxismo como historicismo, y cómo afecta la cuestión de la categoría de irracionalidad en el análisis predictivo y controlador del historicismo. En tal sentido se hace una revisión y contrastación teórica y se analizan sus principales postulados al respecto. Se concluye haciendo una deconstrucción de la interpretación mecanicista del marxismo y se establece la pertinencia de un marxismo descolonizado desde la ruptura de Marx con el eurocentrismo y la crítica a la racionalidad tecno científica.

Palabras clave: filosofía de la ciencia, marxismo, decolonialidad.

\footnotetext{
${ }^{1}$ Magister en Filosofía. Universidad del Zulia. Asistente académico en la cátedra de "Lógica para un profesional eficiente" de la Escuela de Comunicación Social de la Facultad de Humanidades y Educación, Universidad del Zulia. Venezuela.
} 


\section{THE MARXISM DECOLONIZED AS DECREASE A CRITICISM OF POPPER} HISTORICISM

\section{ABSTRACT}

It is intended to address the critique of Popper towards historicism, developed from his perspective on philosophy of science, conceiving the link between techno-scientific rationality and instrumental rationality in Popperian philosophy. Methodologically, this works reflects on the hermeneutic of Popper on Marxism as historicism, and the way it affects the question of the category of irrationality in the predictive and controlling analysis of historicism.

In this sense, a review and a theoretical contrasting are conducted, and the principal postulates are analyzed. It concludes by doing a deconstruction of the mechanistic interpretation of Marxism and it is established the pertinence of a decolonized Marxism from the rupture of Marx with the Eurocentrism and the critique to the techno-scientific rationality.

Key Words: philosophy of science, Marxism, decoloniality.

\section{Introducción}

El siguiente trabajo de investigación responde a una interpretación de la filosofía de la ciencia de Popper en el aspecto de que su cientificismo está apegado a una racionalidad tecno-científica. Para ello, se comenzará con una introducción a la filosofía de la ciencia como necesaria para comprender la crítica que Popper hiciera a las corrientes historicistas, aunque centralmente su crítica se orienta hacia una detracción del marxismo. Se demostrará el principal aspecto de la crítica al historicismo y cómo la categoría de irracionalidad se asume como central en la filosofía popperiana, la cual no está separada de su concepción de progreso científico, y que en el fondo responde a una defensa del sistema capitalista como orden existente que determina que toda transformación profunda y radical no pueda ser llevada a cabo. Es por eso que la introducción a la filosofía de la ciencia de Popper conectará directamente la cuestión de la defensa del orden existente con el cientificismo popperiano y el método de demarcación utilizado. 
En el segundo aspecto del trabajo de investigación, y que se desprende del análisis del primer aspecto, la filosofía de la ciencia popperiana y la crítica al historicismo, se llevará a cabo una re-interpretación del marxismo como ruptura de una concepción eurocéntrica del mismo. Para ello, se tomará en cuenta qué tipo de marxismo es el que critica Popper con el fin de poder plantear la posibilidad de un marxismo no colonizado, que asume el problema político del poder y la estructura económica y social de las regiones semi-coloniales, como lo es América Latina.

La ruptura con un marxismo colonizado necesita de un debate con respecto a las experiencias históricas que han llevado al fracaso de la propuesta emancipadora. En este estudio se tomará en cuenta la cuestión de la racionalidad tecno-científica en su relación al paradigma moderno occidental como punto de referencia para determinar las causas del fracaso y analizar las posibilidades no eurocéntricas de plantear nuevamente una alternativa al sistema capitalista.

De allí se devendrá en la crítica que hiciera Gramsci (2012) y Trotsky (1975) a la perspectiva estalinista, haciendo énfasis en la cuestión de la hegemonía y el problema de la revolución en los países periféricos a la centralidad capitalista. De esta forma, asumiendo una visión alternativa al totalitarismo, la crítica de Popper al historicismo es criticada por la presentación de un marxismo que toma en cuenta la multiplicidad y la diferencia, y no cae en el determinismo y mecanicismo que criticara este filósofo. Por ello, se finalizará con la exposición de esta problemática, en cuanto el marxismo des-colonizado sea expresión detractora de la crítica de Popper hacia el historicismo, y por ende, hacia el marxismo.

\section{Introducción a la filosofía de la ciencia de Popper}

Comenzar con una introducción a la filosofía de la ciencia de Popper permitirá entender el alcance de la crítica al historicismo desde el concepto de irracionalidad, el cual está unido al método lógico de la propuesta de Popper y al concepto de falsabilidad como forma de concebir el progreso de la ciencia. Para comprender la introducción a la filosofía de la ciencia de Popper se toma los cuatros puntos centrales que asume Gómez (2005): la racionalidad instrumental, 
el método crítico, la progresividad y la logicidad. Estos cuatros puntos son los básicos en cuanto filosofía de la ciencia de Popper, y también son aquellos que permiten que esta introducción a la filosofía de la ciencia de Popper se relacione con la crítica que hiciera este filósofo vienés al marxismo, en cuanto lo considera un historicismo. A continuación se desarrollara cada uno de estos cuatros conceptos con la finalidad de poder encontrar en cada uno un mayor conocimiento en forma general del significado de la filosofía de la ciencia de dicho autor, siempre rechazando realizar un reduccionismo de la obra filosófica de Popper.

Se comienza por la racionalidad instrumental, la cual es recogida críticamente por Horkheimer (1973) en su libro Crítica de la razón instrumental, en el que la misma está en función de un adueñarse de la naturaleza. Siguiendo el trabajo de Gómez (2005), se plantea que la ciencia tiene un fin en específico que consiste en encontrar la verdad. Realizando un análisis del concepto de verdad, lo cual no resulta un trabajo fácil debido a la complejidad de situaciones en donde la palabra es empleada, se tiene que hacer un acercamiento a la etimología de verdad en la antigua Grecia, en la que esta era reconocida por el concepto aletheia. El significado de tal palabra hace referencia a des-ocultar la realidad, a des-velarla, es decir, que ir hacia la verdad, tener a la verdad como fin, tiene que venir acompañada por un proceso que des-oculte esa realidad, que en cierta forma la filosofía merleaupontiana de la percepción consiste en esta práctica, en iluminar la oscuridad que es un sinónimo del desconocer².

En el presente, el tema o cuestión de la verdad está cruzado por una serie de debates que dan cuenta de la crítica al referente, del relativismo epistemológico, y demás cuestiones que no ameritan desarrollarlos aquí, debido a que no es el fin de esta investigación. Por ello, cuando se hace referencia a que la ciencia, en este caso la ciencia occidental, tiene como fin buscar la verdad, se está queriendo decir que el interés de la misma consiste en conocer esa realidad, en determinar las leyes que hacen posible un mejor entendimiento del mundo. La ciencia occidental quiere racionalizar el mundo, desde su concepción logocéntrica

${ }^{2}$ Esta concepción está en analogía con la filosofía platónica, especialmente con el mito de la caverna. 
cartesiana, porque el propio método cartesiano es la base fundamental del análisis, es decir la separación del problema en las unidades menores para tener una mayor comprensión de la cuestión.

Esta racionalidad instrumental para aproximarse a la verdad no es considerada una metodología aislada o una práctica que no tenga en cuenta cierta forma cultural de concebir al saber. Es en Aristóteles donde el saber no era considerado de una única forma, es decir, la típica identificación entre saberconocimiento, ya que el Estagirita concebía a dos tipos de conocimiento: el teórico y el práctico. El primero de ellos se subdivide entre ciencia, inteligencia y sabiduría, lo que se expresa en un saber por el saber. El segundo, es el conocimiento práctico, que se subdivide en técnica y prudencia, lo que se considera o expresa en producir cosas (técnica o arte), o conducir la vida ética (prudencia o phrónesis). En La Condición posmoderna, Lyotard (1993), plantea que el saber excede a la ciencia y al conocimiento, con lo que se demuestra que el saber no es idéntico al conocimiento o la ciencia, aunque sean parte de ella.

El reconocimiento de que el saber no es igual al conocimiento, y que el mismo está más allá de saber, es decir, que en la filosofía de Aristóteles el saber se subdividía en diferentes conocimientos, y que en el posmodernismo es entendido como abarcativa de otros tipos de saberes. La ciencia y el conocimiento, lleva a interpretar a la racionalidad instrumental que toma en cuenta Popper para su filosofía de la ciencia como un método que está configurado por una forma en específica de concebir al saber. Por ello, tal como lo analiza Gómez (2005):

Si tal objetivo es acercarse a la verdad, es decir, progresar hacia ella, Popper estatuye que el mejor instrumento para ello es el método científico que, en su versión del mismo, es el método crítico de conjeturar hipótesis para resolver problemas y aceptar sólo aquella que resiste a nuestros intentos de refutarla. ( $p$. 90)

Si Gómez (2015) considera que el mejor método o instrumento para acercarse a la verdad resulta ser el método científico en la filosofía de Popper, se está comprendiendo cómo actúa la configuración del saber por la episteme moderna. En otras palabras, la concepción de la ciencia como saber fundamental para conocer la realidad y que se encuentra en la cima de la jerarquía del saber en 
occidente. El problema de Popper es que no concibe la relación que existe entre la verdad y el poder, por lo que esta razón instrumental es demostrada por el autor desde una neutralidad que a fin de cuenta no lo es, por el hecho de que "la verdad interactúa con el poder. Los creadores, poseedores y administradores de la verdad siempre han sido quienes -de una u otra manera- ejercieron el poder político, económico, represivo, religioso o tecnocientífico" (Díaz, 1996, p. 24).

La no neutralidad de la ciencia como muestra de una de las primeras contradicciones de la filosofía de la ciencia en Popper, lleva directamente al segundo aspecto que indicara Gómez (2005), el del método crítico. Este método crítico basado en la racionalidad instrumental es aquel que determina la veracidad de la teoría o hipótesis por medio de la refutación de la misma, debido a que de ella se pueden determinar lo siguiente:

Si la decisión es positiva, esto es, si las conclusiones singulares resultan ser aceptables, o verificada, la teoría a la que nos referimos ha pasado con éxito las contrastaciones (una por vez): no hemos encontrado razones para desecharla. Pero sí la decisión es negativa, o sea, si las conclusiones han sido falsadas, esta falsación revela que la teoría de la que se han deducido lógicamente es falsa. (Popper, 1980, p. 33)

Aquí se expresa la relación entre la conjetura (hipótesis) y la refutación (falsabilidad), en el hecho de que lo que se supone como explicación o solución de un problema debe ser contrastado. Ello siempre y cuando se conciba que toda teoría para ser científica debe tener esta posibilidad de ser refutada, es decir, que no se acepta como científica a aquellas teorías o hipótesis que no puedan ser refutadas. Esto abre las puertas para el siguiente aspecto, ya que si las hipótesis o teorías que se aceptan son aquellas que han pasado todas las refutaciones, entonces el progreso de la ciencia de Popper debe ser leído como un avance racional, basado en la conjetura-refutación y la concepción de la racionalidad instrumental ${ }^{3}$. Por ello, en función de determinar el progreso de la ciencia, para Popper "el criterio de demarcación que hemos de adoptar no es el de la verificabilidad, sino el de la falsabilidad de los sistemas" (Popper, 1980, p. 40).

\footnotetext{
${ }^{3}$ Esto se demuestra más adelante en la concepción de progreso basado en una racionalidad tecnocientífica, la cual se basa en un aspecto fetichista del mismo, en sobrevalorar un punto determinado y de allí argumentar las conclusiones.
} 
Al comprender la racionalidad instrumental, el método crítico y la progresividad, se hace necesario pasar al siguiente y último aspecto, el de la logicidad. La relación entre lógica y verdad no es una reflexión propia de Popper y menos en filosofía la creencia en encontrar la estructura lógica del mundo, y que con la filosofía del lenguaje se avance en encontrar esa estructura en el lenguaje como forma de conocer la realidad. Siguiendo la relación entre lógica y ciencia, para Popper el método inductivo, que era predominante en las ciencias experimentales, no resulta ser el más adecuado, y por ende establece al método deductivo, especialmente al modus tollendotolens ${ }^{4}$, como aquel que permite la corroboración de las hipótesis o teorías mediante la refutación de las mismas.

Explicados y desarrollados estos aspectos de la filosofía de la ciencia de Popper, es lo que permite entender a la misma como forma introductoria para pasar a desarrollar la crítica al historicismo. De esta forma, se comprende mejor las incidencias de tal filosofía de la ciencia con respecto a uno de los puntos centrales de la crítica al marxismo: la categoría de irracionalidad. La crítica al irracionalismo está desarrollada en su crítica al postkantismo, y la concepción del rechazo de la posibilidad del conocimiento en Kant, porque "sabemos por Kant que la razón humana es incapaz de captar o conocer el mundo de la cosa en sí" (Popper, 1991, p. 240). Entonces, sino no se puede conocer esa cosa en sí, serán por medios irracionales que es posible, como lo afirma Popper (1991). No obstante, para Kant el conocimiento es posible por el sujeto trascendental, porque "la capacidad de conocer del ser racional le permite sintetizar (ordenar en una unidad) la multiplicidad de la experiencia (Como se cita en Díaz, 1996, p. 106).

\section{La crítica al historicismo}

La crítica al historicismo es expresada por Popper $(1987,2010)$ en sus libros La miseria del historicismo y La sociedad abierta y sus enemigos ${ }^{5}$. En estos libros se desarrolla una crítica a cierta interpretación de la historia, que en alguna forma constituye una filosofía de la historia. Además, ambos libros cumplen un

\footnotetext{
${ }^{4}$ La traducción del mismo quiere decir modo que negando niega.

${ }^{5}$ Ambos libros mantienen la lógica ideológica de crítica al historicismo.
} 
papel ideológico que termina por justificar el orden establecido y deslegitimar cualquier cambio profundo y radical de las estructuras presentes. Es por ello que se le considera una ideología en el sentido marxista del concepto, porque cumple la función de ser un velo que cubre una realidad y expresa una realidad invertida. Esta realidad invertida no permite una apreciación profunda de las condiciones materiales que son en última instancia determinantes de las expresiones superestructurales, y por esta situación esa inversión de la realidad termina por encubrir las razones de fondo y así justifican el orden existente.

Entrando directamente en la crítica al historicismo, el cual se desprende de la filosofía de la ciencia de Popper que anteriormente fue explicada y desarrollada, es entonces cuando se explica la interpretación que hiciera Popper del historicismo, que entiende como:

Un punto de vista sobre las ciencias sociales que supone que la predicción histórica es el fin principal de éstas, y que supone que este fin es alcanzable por medio del descubrimiento de los ritmos o los modelos, de las leyes o las tendencias que yacen bajo la evolución de la historia. (Popper, 1987, p. 17)

El historicismo para Popper es una perspectiva sobre las ciencias sociales, es decir, una forma de ver y concebir a las mismas, teniendo en cuenta que su finalidad consiste en la predicción histórica, que es lograda gracias al descubrimiento de leyes o tendencias. De esta forma, el historicismo comprende a todas aquellas teorías que parten de una predicción de los fines históricos basados en un descubrimiento de un movimiento interno de tal fenómeno. Ese movimiento interno de la historia es concebida como aquellas regularidades que permitirían conocer la razón de ese acontecer histórico, y que en cierta analogía con las ciencias naturales se podrían aprender en función de dominar a esos fenómenos históricos sociales. Es un conocer para dominar ${ }^{6}$.

La crítica de Popper, tal como lo señalamos anteriormente, es una crítica a una concepción filosófica de la historia que posee la característica de ser teleológica; su análisis está en función de determinar los fines de la historia. La filosofía de la religión cristiana y las consecuencias que tiene la misma sobre la interpretación histórica, llevan a considerar a que se conozca antes de que ocurra

${ }^{6}$ Esta posición es reconocida en Horkheimer y su crítica a la razón instrumental como apropiación del mundo natural. 
el hecho, a priori. La finalidad del mismo, por el hecho de conocer las leyes históricas sociales o en el caso de la religión cristiana a la palabra sagrada. La segunda llegada de Jesús a la tierra es un acontecimiento que antes de ser ocurrido es conocido e interpretado con un carácter verídico por esta filosofía de la religión y ese conocimiento está legitimado en los análisis de la palabra sagrada materializada en la Biblia.

Más allá de los juegos del lenguaje propios de la filosofía cristiana, de las reglas internas que dotan de sentido el discurso cristiano y su interpretación histórica. Existe una orientación epistemológica a determinar a las causas finales desde una voluntad de verdad basada en el conocimiento de las leyes internas. Conocer esas leyes internas permiten sostener con mayor argumentación esa finalidad que pareciera ser indetenible y a la cual someter la razón crítica en función de una mejor preparación para tal momento. Las consecuencias epistemológicas de esta filosofía de la historia se reconocen en una consecuencia ética, porque importa el actuar para poder tener cierto margen de maniobra frente a un hecho que se va a consumar, del cual no se puede escapar, pero sobre el cual se puede actuar. Por ejemplo, no hay consenso acerca de la fecha exacta de la llega de Jesús para el cristianismo, pero sí hay consenso en que llegará.

Pareciera ser que el centro de la crítica que hiciera Popper del historicismo es su voluntad de predicción, pero, tomaremos otro punto. Aunque destaquemos que el filósofo vienes sea un crítico, esta concepción predictiva de las ciencias sociales llevada a cabo por el historicismo. El punto que se tomará como parte de la comprensión que se tiene sobre el irracionalismo se desprende de la concepción del progreso en la ciencia, y por ende de su canon teórico que fue desarrollado en la primera parte de la investigación, es decir, en la introducción a la filosofía de la ciencia de Popper. Se destaca este segundo aspecto por el hecho de que lo irracional permite entender lo predictivo y que además expresa un sentir de la ciencia occidental con respecto a la dualidad racional/irracional. Este parte con la introducción y desarrollo de la razón occidental, del logocentrismo cartesiano que es un fundante de la razón tecno-científica que hoy conocemos, por el hecho de establecer la duda racional. 
Este irracionalismo que es el centro de la crítica de Popper al historicismo se expresa en que el filósofo vienes entenderá al progreso de la mano de la racionalidad. Si en su filosofía de la ciencia el progreso de la misma se comprendía desde la conjetura-refutación, desde la generación de hipótesis y su posterior puesta a prueba, entonces se estaría desarrollando un progreso que es entendido como racional. Por ello, se toma en cuenta para entender la lógica de la racionalidad y el progreso que:

En resumen, y de acuerdo al criterio popperiano de racionalidad, las revoluciones científicas son siempre racionales, las revoluciones sociales totales siempre irracionales, mientras que las revoluciones ideológicas pueden ser una u otra cosa, dependiendo de su funcionalidad al progreso científico. (Gómez, 2005, p. 95)

Gómez desarrolla su estudio sobre el tema de la irracionalidad en la crítica de Popper al historicismo mediante un análisis de las revoluciones en la filosofía del vienes, y ha tomado como punto de análisis tres tipos diferentes de revoluciones. La primera de ella consiste en las científicas, que son racionales por el hecho de utilización del método de la conjetura-refutación. Las segundas, las revoluciones sociales son irracionales, y las terceras terminan por ser relativas, es decir, que están función de la relación con respecto al progreso científico. En la distinción que hace Popper de las revoluciones científicas y las revoluciones sociales, sostendrá que las segundas:

Mientras estas violan el método científico gradualista propio de las ciencias sociales, las revoluciones científicas no lo hacen, en tanto siempre que se produce un cambio científico, el mismo se lleva a cabo de acuerdo a las pautas de proponer nuevas conjeturas que reemplazan a aquellas ya refutadas. (Como se cita en Gómez, 2005, p. 94)

La distinción que existe entre ambas revoluciones, entre las científicas y las sociales, es que las primeras no violan el método científico de que una teoría o hipótesis suplanta a la anterior, mediante la demarcación por falsabilidad. Por el contrario, las segundas, las sociales, violarían el método científico y, por lo tanto, habría una ruptura de la tradición. Esto lleva a que debamos comprender que "la racionalidad que se utiliza para evaluarlas involucra no ruptura radical con la tradición, por lo que sólo la reforma gradual, con preservación de lo anterior es racional, tanto en el plano empírico natural, como social" (Gómez, 2005, p. 95). Las revoluciones científicas romperían la tradición y la reforma gradual, por lo que 
conocería la razón de considerarlas irracionales desde la perspectiva popperiana de las revoluciones.

Continuando con la temática de la tradición, una de las tradiciones de las ciencias sociales sería la tecnología social fragmentaria. En el libro La miseria del historicismo se comprende a la misma como enfrentada con respecto a la ingeniería utópica. Para comprender la diferencia que estipula Popper (1987) se verá que por ingeniería utópica entiende que:

La ingeniería social utópica u holística, como opuesta a la ingeniería social fragmentaria, nunca tiene un carácter "privado», sino sólo "público». Basta remodelar a "toda la sociedad» de acuerdo con un determinado plan o modelo; busca apoderarse de las posiciones claves y extender «el poder del Estado (...) hasta que el Estado identifique casi totalmente con la sociedad», y busca, además, controlar desde esas «posiciones clave» las fuerzas históricas que moldean el futuro de la sociedad en desarrollo: ya sea parando ese desarrollo, ya previendo su curso y adaptando la sociedad a dicho curso. (pp. 81-82)

La irracionalidad de las revoluciones sociales consiste, en esta problemática, en el hecho de que las mismas se orientan hacia una transformación de la totalidad, desde una radicalidad que caracteriza al fenómeno social como transformador de lo existente por algo nuevo. Entonces, la irracionalidad es no seguir el camino de la tradición, de la tecnológica social fragmentaria que es considerada según el autor en la función del ingeniero fragmentario, según la cual se puede comprobar lo siguiente:

El ingeniero fragmentario sabe, como Sócrates, cuán poco sabe. Sabe que sólo podemos aprender de nuestros errores. Por tanto, avanzará paso a paso, comparando cuidadosamente los resultados esperados con los resultados conseguidos, y siempre alerta ante las inevitables consecuencias indeseadas de cualquier reforma; y evitará el comenzar reformas de tal complejidad y alcance que le hagan imposible desenmarañar causas y efectos, y saber lo que en realidad está haciendo. (Popper, 1987, p. 81)

Reconocida la diferenciación entre la tecnología fragmentaria y la ingeniería utópica, se podrá desarrollar el aspecto del marxismo en clave determinista y positivista. Si las críticas de Popper en contra del historicismo es contra la irracionalidad predictiva y controladora de la transformación social de las teorías historicistas, principalmente del marxismo, entonces se debe reconocer que ese marxismo que es criticado por Popper representa una interpretación en clave determinista y positivista, lo que refleja la posición ideológica de la teoría 
popperiana en cuanto que su interpretación está en función desprestigiar al marxismo como filosofía de la praxis. Por lo tanto, construir un discurso que favorezca el orden existente y no solo por el decir, sino principalmente por su lógica argumentativa interna, la de negar toda transformación general de la sociedad $^{7}$.

\section{La ruptura del marxismo con el eurocentrismo}

La crítica al historicismo se vuelve una crítica al marxismo, siempre interpretado desde una lógica positivista y determinista, en tanto expresión irracional que desea poseer el control de la totalidad y hablar en tono de transformación radical de la sociedad. Sin embargo, el problema se vuelve más profundo, cuando aunado a la crítica de la irracionalidad del marxismo se realiza una interpretación desde una perspectiva estalinista, es decir, que se rescata a un marxismo mecanicista y unilineal $^{8}$. Entonces, la crítica al historicismo se empalma con una crítica a cierta lógica del marxismo que actúa como un inhibidor de la potencialidad de transformación que tiene tal filosofía de la praxis. Por un lado se crítica un aspecto irracional, siempre desde la racionalidad científica y, por otro lado, especialmente desde el margen o periferia de la centralidad capitalista, se critica el carácter eurocéntrico de tal teoría.

Si en la primera cuestión el marxismo es un historicismo, es en la segunda en la que se asume una interpretación que tiene un carácter equivocado de tal filosofía de la praxis, ya que toma en cuenta una variante mecanicista y determinista de la misma, el estalinismo. La teoría crítica latinoamericana actual, la decolonial, considera al marxismo en identificación con la corriente estalinista en la que se puede observar que:

Todos los integrantes de la corriente decolonial, y por ende los del indianismo o indigenismo, comparten el presupuesto de que el marxismo sería una variedad del pensamiento euro centrista y que esto se expresaría en una visión evolucionista unilineal de la historia, donde las etapas del desarrollo europeo necesariamente se deberían repetir en los llamados países de desarrollo industrial rezagado o semicoloniales. (Ferreira, 2010, pp. 65-66)

\footnotetext{
${ }^{7}$ Este es el nudo central de la crítica al historicismo, la de negar cualquier tipo de transformación del sistema que no sea de forma gradualista.

${ }^{8}$ Este marxismo mecanicista es el que surge luego de la instalación de la III Internacional como dirigente a Stalin, determinando una política etapista como estrategia política.
} 
Queda bien claro que la corriente decolonial sugiere que el marxismo es un corriente que se caracteriza por su propuesta de evolución unilineal de la historia, además por la inevitabilidad de que el margen del sistema debe pasar por las mismas etapas por la que ha pasado la centralidad capitalista. La semicolonialidad sería un peldaño que debe ser superado, y para superar tal peldaño se necesita pasar por las mismas condiciones que los países centrales. Resulta una interpretación mecanicista del proceso global del capitalismo, ya que por el mismo es que se entienden las relaciones de opresión de la centralidad con respecto a la periferia, y estas relaciones son aquellas que sustentan el patrón de acumulación actual, y por ende no representan una mera contingencia.

Esta caracterización que tomó en cuenta el estalinismo convierte al marxismo en un mero conocedor de supuestas leyes internas que serían invulnerables por cualquier tipo de práctica política, y por ende se debe un pasivo sometimiento a las mismas. El hecho que exista un pasivo sometimiento no significa que no exista una voluntad política, una estrategia o táctica, sino que la misma estaría condicionada a la dinámica de la dialéctica atraso-avance. Esta voluntad política es la que se conoce como estalinismo: "esta visión etapista de la historia se basaba en un rígido esquema de sucesión lineal y "obligatoria" de estadios históricos, vulgarizando y dogmatizando al extremo a Marx." (Ferreira, 2010, pág. 66). El etapismo es el determinante de la voluntad política del estalinismo, y desde allí es que se entiende la razón de ser de esta corriente política que apuesta a un desarrollo unilineal.

El estalinismo concibe a la revolución social como una transformación gradual que debe pasar por etapas, por ello su carácter etapista ${ }^{9}$, con la finalidad de desarrollar las fuerzas productivas en el capitalismo. De esta forma, asemejarse a las condiciones sociales de la centralidad capitalista, y por esta vía repetir aquello que Marx ha establecido en el Manifiesto Comunista, donde establece que:

\footnotetext{
${ }^{9}$ La estrategia estalinista se caracteriza por la alianza de la clase obrera con la burguesía nacional en un frente nacional antiimperialista, para luego desarrollando las fuerzas productivas, hacer una revolución socialista.
} 
Las armas de que se sirvió la burguesía para derribar al feudalismo se vuelven ahora contra ella. Pero la burguesía no ha forjado solamente las armas que deben darle muerte; ha producido también los hombres que manejan esas armas: los obreros modernos, los proletarios. (Marx y Engels, 2000, p. 37)

Ello significa que ese desarrollo capitalista no es otra cosa que una lectura fenomenológica del capital, en otras palabras, un movimiento del mismo que genera a su enterrador, el proletariado moderno. El capital, al igual que espíritu hegeliano, se auto-mueve por la historia, y en su proceso de objetivación conforma a su negación, el proletariado. Para construir el socialismo, desde la perspectiva estalinista, se debe en primer lugar pasar por este desarrollo capitalista; de esta forma se conforme aquel enterrador del capitalismo, el proletariado. El problema principal que de esta teoría política se desprende corresponde a que no toma en cuenta las condiciones internacionales de la relación capital-trabajo y que la construcción del socialismo excede las barreras nacionales. Por ello se toma en cuenta que:

Las fuerzas productivas actuales hace ya tiempo que han rebasado las barreras nacionales. La sociedad socialista es irrealizable en los límites nacionales. Por importantes que puedan ser los éxitos económicos de un Estado obrero, el programa del -socialismo en un solo país- es una utopía pequeño burguesa. Sólo una federación europea, y después mundial de repúblicas socialistas, puede abrir el camino a una sociedad socialista armónica. (Trotsky, 1975, p. 92)

Más allá de que las críticas al marxismo partan de una interpretación del mismo en clave estalinista, se debe ver que en Marx existe una concepción eurocéntrica en cierta parte de su desarrollo teórico. El Manifiesto Comunista revela en cierta forma esta actitud de la teoría marxista hacia una interpretación eurocéntrica del desarrollo histórico, la cual descansa en la filosofía hegeliana de los pueblos sin historia, quienes se han quedado fuera del automovimiento del espíritu hasta su autoconciencia. Lo que ha quedado al margen de ese automovimiento, en este caso la periferia de la Europa occidental, no posee historia, y por ende tampoco Estado. El Estado sería la autorrealización del espíritu, y desde aquí es que se dividen los hegelianos de izquierda y derecha, entre los primeros Marx ${ }^{10}$.

\footnotetext{
${ }^{10}$ De aquí se desprende que los hegelianos de derecha conciban que el Estado burgués que se va consolidando en Europa en la primera mitad del siglo XIX será el Estado configurado por la 
La dualidad de la civilización y barbarie está presente en el Manifiesto Comunista, lo que recuerda a la obra de Sarmiento (1993), El Facundo. Esta dualidad es expresión directa de una comprensión filosófica eurocéntrica, y asumiendo desde este re-ordenamiento del mundo una subvaloración de aquello que se considera bárbaro. Partir desde esta concepción termina por determinar a la contingencia de las relaciones asimétricas que se sostienen en el modo de producción capitalista como formas ajenas al modo de reproducir la vida social y, por ende, toda crítica de tal relación que no toma en cuenta las condiciones materiales para su existencia terminará fetichizando tal relación asimétrica, e imposibilitando una interpretación para una posterior transformación.

Esta concepción eurocéntrica es la que asume el estalinismo como corriente política, y es la que los estudios decoloniales asumen como característica del marxismo. Esta posición puede verse claramente en cómo los teóricos de esta escuela analizan críticamente al marxismo, realizando una lectura en clave eurocéntrica del mismo, sin tomar en cuenta la ruptura que hiciera Marx. Por ello, se puede entender este proceso crítico tomando en cuenta lo siguiente:

A pesar de lo acertado de sus cuestionamientos al capitalismo, al marxismo se lo considera atrapado en el eurocentrismo al hacer énfasis en la clase social como categoría analítica, extrapolandoy universalizando una experiencia histórica europea al resto del mundo, desconociendo elementos como la raza considerada central en la articulación del modo de producción capitalista por fuera de Europa. (Restrepo y Rojas, 2010, p. 29)

Marx termina por realizar una ruptura con el eurocentrismo, aunque estos teóricos no lo tomen en cuenta y prefieran hacer una crítica sobre una ilusión, todo con la finalidad de acomodar sus argumentos a una realidad que no es como tal. Para analizar la ruptura del marxismo se tomará como referente el estudio que hiciera Kohan (2009) de tal ruptura, tomando en cuenta tres niveles, el filosófico, el científico y el político. Cada uno de ellos demuestra dónde Marx termina por realizar una discontinuidad con la lógica eurocéntrica que se ha demostrado, y que se expresa directamente en las cartas que hiciera este filósofo prusiano con respecto a la cuestión colonial.

autoconciencia del espíritu. En cambio, los de izquierda, entre ellos Marx, sostendrían que esa autoconciencia no se había desarrollado en el Estado burgués. 
El primer nivel, el filosófico, establece un elemento que ha estado presente en la filosofía marxista, la filosofía de la praxis. La dialéctica entre la contemplación y la acción, es lo que recoge la onceava Tesis sobre Feuerbach de 1845, en la que llamaba a no sólo interpretar al mundo, sino a transformarlo. Siguiendo este camino, lo que desemboca en su filosofía de la praxis, se demuestra una ruptura de la concepción de progreso, especialmente de aquella que se criticó anteriormente, lo que terminaba por construir una filosofía de la historia con un carácter fetichista. De esta forma, si se realiza un quiebre con esta lógica de interpretación histórica, entontes también se estaría realizando de igual forma y como consecuencia de ello, una ruptura con la tesis hegeliana de los pueblos sin historia, y a si mismo con la dualidad civilizados/bárbaros.

El segundo nivel, el científico, tiene que ver directamente con el aspecto histórico-antropológico y se encuentra vinculado con el apartado anterior, el del nivel filosófico. Para comprender mejor este nivel hay que reconocer que el mismo expresa una forma de concebir lo histórico-antropológico desde un marco de ruptura con el esquema anterior $y$, por ello, se puede entender de mejor forma de la siguiente manera, en la que se concibe directamente el viraje que se desarrolló:

Estamos pensando principalmente en la modificación del esquema teórico de desarrollo y evolución de las sociedades, en la complejización de la noción de "desarrollo histórico" en sus grandes líneas directrices, en la reubicación y el descentramiento de la dicotomía categorial "barbarie-civilización", en la adopción historiográfica de la hipótesis de trabajo del "modo de producción asiático" y del "sistema arcaico" para explicar las sociedades precapitalistas no modernas ni europeas, en el creciente interés económico y etnológico tanto por la comuna rural campesina como por la sociedad denominada "primitiva" $y$, finalmente, en la atenta reflexión y seguimiento de la teoría de la revolución en las ciencias biológicas y en las sociales. (Kohan, 2009, p. 347)

El tercer nivel, el político, también se encuentra en relación a los puntos tomados en cuenta que se presentan como una discontinuidad en el marxismo, tales como la caracterización de la comuna rural rusa, y que permite comprender la cuestión nacional y colonial. De allí es posible que intervengan nuevas subjetividades políticas de las clases subalternas al proceso político en cuestión, principalmente en el aspecto de comprender que el proletariado no es la clase social única dentro del campo de los subalternos, y que existen otras subjetividades que pueden hacer eco en las transformaciones sociales a gran 
escala. Este tercer nivel del esquema de ruptura del marxismo toma en cuenta una dialéctica positiva de apertura hacia nuevos sujetos subalternos en un proceso de emancipación social.

Comprender la ruptura de Marx con el eurocentrismo es concebir que la crítica que se hiciera desde Popper al historicismo (marxismo) en cuanto irracional, por el hecho de querer controlar la totalidad. Por ello, plantear una transformación del orden existente, carece de sentido porque interpreta al marxismo desde una lógica ideológica de querer justificar el orden existente frente a una transformación de fondo y profunda. Esto se complica cuando esa interpretación se asume como un marxismo dogmático, determinista, eurocéntrico y mecanicista, lo cual impide reconocer la progresividad del marxismo en cuanto ruptura del eurocentrismo, y que avanza hacia una política emancipadora que toma en cuenta los aspectos socio-culturales de la periferia de la centralidad capitalista. Entender al marxismo descolonizado y por ende no eurocéntrico es criticar la crítica de Popper al historicismo.

Hay dos textos claves de Marx que son citados por Kohan (2009) en su obra Marx en su (Tercer) Mundo. Hacia un socialismo no colonizado, los cuales se corresponden a dos cartas que escribiera el pensador de Tréveris a Vera Zasuslich y a los populistas rusos. En dichas cartas se respondía a la pregunta por la posibilidad de la regeneración de la sociedad rusa sin tener que acudir al desarrollo de la gran propiedad privada y las formas políticas de la democracia burguesa, de acuerdo con una mirada etapista, como también a las pretensiones universalistas de tal modelo de desarrollo histórico. El filósofo alemán responde que no hay pretensión de un proyecto universalista y ve en la comuna rusa la posibilidad de regeneración de Rusia.

Es por ello que se puede marcar una ruptura de Marx con el eurocentrismo, en la medida que no expresa la irracionalidad de querer controlar la totalidad, sino que su mirada está centralizada en las particularidades, como es el caso de Rusia. Se supera, de esta forma, el contenido ideológico de su mirada sobre el problema nacional en la India bajo dominio de Gran Bretaña o el robo de territorio mexicano por parte de Estados Unidos. Más allá que Marx desde el aspecto ético haya 
estado siempre en consideración con las regiones oprimidas por el imperialismo, su perspectiva eurocéntrica se correspondía con un modelo epistemológico que respondía a un esquema universalista del desarrollo histórico, caracterizado por la fenomenología del capital, como relación social que, al igual que espíritu hegeliano, se auto-mueve por la historia.

\section{El marxismo des-colonizado como crítica a Popper}

Partir de un marxismo des-colonizado es concebir al marxismo en postura crítica frente al argumento popperiano de la crítica al historicismo. Esta operación es posible separando al marxismo de aquella concepción vaga e ideológica que realiza Popper del historicismo, demostrando la pertinencia de un marxismo descolonizado, que escape de la lógica occidental del progreso, de la apertura a las experiencias socio-culturales de la periferia capitalista, y la conformación de una filosofía de la praxis que sea representante de el viraje realizado por Marx. Esto puede caracterizarse en el esquema que realizará Kohan (2009) con respecto al viraje, en el que asume que:

Cuando Marx logra percibir y hacer observable: 1) que no existe una lógica histórica universal al margen de la lucha de clases; 2) que no responde a un sujeto autocentrado y privilegiado -el proletariado europeo, urbano y moderno- la responsabilidad de conducir el motor de la historia universal, sino que ese sujeto está en realidad conformado también por la luchas de liberación nacional y social de los pueblos periféricos sometidos; y 3) que el sistema mundial de dominación capitalista solamente puede reproducirse a condición de mantener la explotación y la opresión tanto en el capitalismo central como en su periferia, es que puede entonces terminar de completar las líneas directrices de aquel inicial programa de investigación esbozado y adelantado en 1845. (pp. 364-365)

El primer punto refuerza el nuevo sentido de la filosofía de la historia marxista que se ha venido profundizando a contracorriente de la concepción mecanicista de un movimiento interno de la historia sin la dinámica de los procesos sociales concretos. Marx y Engels (2000) en el Manifiesto Comunista demuestran el papel del motor de la historia en la lucha de clases, y es de aquí en que esa lógica histórica universal sin tal motor carece de sentido. Aunque el hecho de hablar de lo universal, partiendo de una lógica arbitraria, ya se presenta como una incongruencia porque lo es que mundial o tiende a superar barreras nacionales es el capital. Este está en relación con el trabajo, lo cual frente a 
diferentes investigaciones que han querido modificar esta cuestión, no han podido generar un esquema alternativo que explicará tal situación ${ }^{11}$.

La segunda posee un carácter polémico, ya que si se considera que la relación capital-trabajo es predominante y necesaria para la reproducción del sistema capitalista. Entonces, des-centralizar ${ }^{12}$ a la clase obrera resulta mayor explicación al respecto. La interpretación que se hará de la misma desemboca directamente en dos autores que tienen bastantes puntos en común, Trotsky y Gramsci. Para el revolucionario ruso una revolución debe tomar en cuenta que:

La sublevación no puede conducir a la victoria real de la revolución y a la erección de un nuevo régimen más que en el caso de que se apoye sobre una clase progresiva que sea capaz de agrupar en torno suyo a la inmensa mayoría del pueblo. (Trotsky, 1975, pp. 81)

Esa clase progresiva resulta ser la clase obrera, el proletariado moderno; sin embargo, para que la revolución triunfe y se transmita "el poder de las manos de una clase que está ya agotada a las manos de otra clase en ascenso" (Trotsky, 1975, pág. 81), necesita apoyarse en la inmensa mayoría del pueblo, quienes son parte de las clases subalternas. En el filósofo italiano la constitución de una alianza, el bloque histórico, da cuenta de la necesidad de la clase obrera que debe constituirse en clase dirigente y dominante, siendo dirigente de las clases subalternas aliadas (hegemonía) y dominante de las clases burguesas. Para dirigir debe desarrollar una política de alianzas en la cual los intereses de las demás clases o sectores subalternos estén presentes en la lucha por el ejercicio del poder político, y estos sectores deben ver reflejados sus intereses mediatos e inmediatos en tal clase progresiva.

La cuestión de la hegemonía se puede ver como un punto nodal para pensar la cuestión de la des-colonización del marxismo. Tanto Trotsky como Gramsci, el problema de la hegemonía es central, debido a que para el revolucionario ruso la cuestión pasa por el hecho de que una clase social, como lo

\footnotetext{
${ }^{11}$ Ciertas concepciones posmodernas nos hablan de la desaparición del trabajo asalariado, y otros de la modificación del patrón de acumulación, como es el caso de Lyotard (1993) y su condición posmoderna.

${ }_{12}$ En este trabajo no se considera pertinente hablar de des-centralización de la clase obrera, sino de una apertura hacia la subalternidad, y que la clase obrera no es la única clase subalterna, pero tiene la capacidad y potencialidad, debido a su posición estratégica en la reproducción del sistema, para transformar la realidad.
} 
es el proletariado, debe apoyarse en la inmensa mayoría de los oprimidos, pero es en Gramsci donde se afina esta cuestión. Para el pensador italiano las clases subalternas "no están unificadas y no pueden unificarse mientras no puedan convertirse en Estado" (Gramsci, 2012, pp. 22). El marxismo des-colonizado está atravesado por la cuestión de la hegemonía, en cuanto las clases subalternas para unificarse deben volverse en Estado, en otras palabras, derrocar a la clase capitalista y asumir el poder político y económico. Es por ello que frente al problema de la hegemonía y la alianza de clase, en trabajos anteriores, se considera lo siguiente:

El desarrollo de esta alianza de clases permite generar un consenso en ellas en la articulación de un programa revolucionario de ruptura y transición al socialismo, pero también que la necesidad de tal alianza se desprende de las condiciones nacionales y sociales. El marxismo latinoamericano debe ser re-pensado desde la dialéctica entre la cuestión nacional y la cuestión social, asumiendo el análisis de Gramsci en cuanto hace posible una lectura marxista en clave revolucionaria del capitalismo periférico, y pone el énfasis en la conformación de un sujeto emancipador comprendido desde la intersubjetividad, pero sin dejar de tomar en cuenta para su análisis las bases materiales de tal tipo de sociedad. Fuera de toda heterodoxia propia de los marxistas latinoamericanos, se quiere concebir la pertinencia epistemológica de un marxismo que tome en cuenta las condiciones sociales y nacionales, y la filosofía de Gramsci como pensador de la periférica capitalista permite concebir tal pertinencia. (Sicerone, 2015a, párr.24)

La última referencia que hiciera Kohan (2009) en base al viraje realizado por Marx descansa en la idea de una totalidad incluyente y relacionante de las partes. No se puede entender el fenómeno de la semi-colonia sin comprender los lazos y relaciones que llevan a considerar a los países dominantes como semicolonizantes; de tal relaciones se puede caracterizar que las clases dominantes de los países centrales del capitalismo oprimen a la periferia y que sin esta relación el capitalismo no podría sostenerse en su fase actual. Las guerras actuales y la ofensiva imperialista demuestran el grado de intolerancia del capital en una estrategia de dominación global y expansión del capitalismo tardío con la precarización del trabajo, lo que se expresa en una precarización de la vida social, en una modernidad líquida a decir de Bauman (2002).

La des-colonización del marxismo no sólo debe quedarse en este esquema, ya que hay un elemento central para que se pueda hablar de descolonización, y es el tema de la racionalidad tecno-científica propia del capitalismo central, y de la 
que Popper no puede escapar cuando su cientificismo parte de considerar a la racionalidad instrumental como relevante en su conformación teórica. Esto lo advierte Lanz (1998) en su crítica al socialismo burocrático, donde sus conclusiones sostienen que:

Las experiencias históricas más recientes que prometieron fundar otro modelo de sociedad, por tanto, una manera diferente de producir y consumir (el socialismo burocrático que ahora se derrumba) han sido -paradojalmente- la patética confirmación del mismo modelo tecnológico productivista impuesto en Occidente. Es por eso que el socialismo burocrático no puede ser nunca un sistema alternativo frente a la civilización del capital (cuya expansión planetaria opera hoy casi sin ninguna oposición en todos los rincones de la tierra). (p. 146)

El socialismo burocrático no ha podido superar la racionalidad tecnocientífica que se ha instalado en Occidente, y menos aún el esquema del progreso en razón del crecimiento de las fuerzas productivas, concibiendo un fetichismo del progreso. La descolonización es entender que el problema es que no hay una razón absoluta, universal, porque en la modernidad "la razón se transmuto en Progreso asegurado por el incesante desarrollo de las fuerzas productivas en la forma de una tecno-ciencia universal, impoluta y buena por definición" (Lanz, 1998, p. 141). Este pensador venezolano inserta un debate que hace posible repensar la sociedad postcapilista, ya que las experiencias históricas demuestran los limitantes del socialismo burocrático, pero también del capitalismo.

El marxismo des-colonizado no puede pensar en posturas medias, en un capitalismo con rostro humano, debido a que en la relación capital-trabajo, lo que se enfrenta no permite que existan posturas intermedias, y todo intento de desarrollar esa vía termina dentro de los límites de la economía basada en la propiedad privada. Este es el gran problema del socialismo del siglo $\mathrm{XXI}^{13}$ como crítica al socialismo burocrático y al capitalismo, pero en la práctica no avanza más allá de la re-distribución de la riqueza y de cierto intervencionismo estatal, y menos propone una ruptura con la estatalidad burguesa. Por ello, la emancipación de los trabajadores será obra de los trabajadores mismos, de su auto-organización y de la lucha de clases, y no de la cientificidad de un marxismo en clave tecnocientífica. Tampoco de un neomarxismo pragmático posmoderno, que fragmenta

\footnotetext{
${ }^{13}$ La experiencias venezolanas y bolivianas demuestran que no representan un alternativa al capitalismo, determinando un modelo nacionalista burgués.
} 
la realidad y por lo tanto las estrategias políticas, lo que se convierte en una micropolítica. Esta propuesta posmoderna recae en perspectivas sobre el sujeto como el concepto de Multitud negreano, el cual es criticado por Bensaid (2006) como filosóficamente confuso, sociológicamente inconsistente y estratégicamente hueco.

Para ello se rescata "la puesta neurálgica de la filosofía merleaupontyana: la superación de todo dualismo" (Eiff, 2010, p. 4) lo que alejaría al marxismo de las concepciones mecanicistas que ponen el centro de debate acerca del progreso en las fuerzas productivas. Así como también comprender la crítica que hiciera Merleau-Ponty al marxismo, en la que la centralidad de la misma "es haber abandonado la filosofía en pos de la ciencia" (Eiff, 2010, p. 7). Con respecto a esta última interpretación, se debe entender dese la generalidad, porque Marx, tal como se ha mostrado, ha presentado una ruptura con el cientificismo en clave positivista, y ha tomado el camino de una filosofía de la praxis. El problema persiste en el hecho de que el estalinismo ha sido dominante en el hecho de caracterización y divulgación del marxismo en tal aspecto, lo que hace posible la crítica de Merleau-Ponty $^{14}$ y de Popper, aunque ambas sean diametralmente diferentes.

Es en estos debates en el que el marxismo se ve cuestionado por la historia de los procesos sociales donde las masas intervienen masivamente en el quehacer político. Tal como se manifestaba anteriormente, ese es el problema que tiene el socialismo del siglo XXI, en cuanto en el ámbito económico no avanza hacia la creación de valor, auspiciando un modelo de reprimarización de la economía, y un crecimiento de los niveles de endeudamiento internacional, y un proceso de crecimiento de las importaciones. Es en este debate en que la descolonización del marxismo debe superar el aspecto epistemológico, en cuanto programa político y económico debe contrarrestar los problemas estructurales que se basan en un capitalismo semi-colonial dependiente. Por ello, no basta con la crítica neo-marxista que deviene en un pragmatismo, y menos una propuesta

\footnotetext{
${ }^{14}$ Merleau-Ponty dirige la crítica desde una fenomenología, y critica la concepción científica que termina por barrer a la filosofía. 
teórica de intervencionismo estatal burgués. Es aquí el reto del marxismo como proyecto emancipatorio.

Un análisis profundo de la realidad boliviana, específicamente bajo la perspectiva de Ferreira (2010), demuestra que la similitud que existe en el proceso de reprimarización de la economía, el aumento de las importaciones y el proceso de burocratización de la economía, no expresa en absoluto una des-colonización del marxismo. Esto más allá de que los gobiernos populistas latinoamericanos incluyan en sus discursos de gobierno a la multiplicidad de sujetos que conviven en América Latina. Los discursos decoloniales des-centralizan al sujeto del cambio social en una región semi-colonial, el cual no puede recaer en sectores de la burguesía nacionalista, ya que esta clase se ve atrapada en el ámbito de la reforma, por el hecho de que no puede ir contra su propia existencia, es decir, las relaciones sociales de producción capitalista. Por lo tanto, sólo la clase obrera, en toda su multiplicidad y diferencia, auto-organizada, y sus herramientas políticas, podrán ser sujeto de cambio social, porque su subsistencia depende de la relación con el capital. De ahí que un proceso revolucionario, exigiría el cambio de clase en el poder, conformando así un proceso de disolución de las formas opresivas, y la apertura a un proceso de gestión directa de la propiedad por parte de los productores, tanto de la ciudad como del campo.

En esta misma línea, Trotsky discutiendo sobre la problemática de las aspiraciones democráticas en países coloniales y la lucha por el socialismo, se puede resaltar su apreciación sobre las tareas democrática burguesas. Si estas son llevadas por direcciones políticas que provengan de sectores capitalistas, así sean anti-imperialistas, no significan que puedan aspirar a transformar la estructura económica hacia la expropiación de la propiedad privada. Eso lo demostró la revolución de febrero de 1917, donde el régimen del Zar fue derrocado, y se instauró una democracia burguesa, pero los problemas agudos de Rusia, como era la cuestión de la hambruna, la tierra, y la guerra inter-imperialista, no podían ser resueltos por la clase capitalista. Por ello, fue en octubre, con la revolución bolchevique, donde el régimen se trastocó, en función de ascenso al 
poder de los soviets, es decir, los organismos de poder obrero, campesino y de soldados. Ante ello Trotsky (2010) dirá lo siguiente:

Las tesis señalan muy correctamente que en Rusia fue la Revolución de Octubre la que solucionó el problema nacional. Los movimiento democráticos nacionales eran importantes de por sí para liquidar por su cuenta la opresión nacional del zarismo. Sólo porque el movimiento de las nacionalidades oprimidas y el movimiento agrario del campesinado dieron al proletariado la posibilidad de tomar el poder y establecer su dictadura, la cuestión nacional y el problema agrario encontraron una definitiva y audaz solución. (p.162)

\section{Conclusión}

La filosofía de la ciencia de Popper es el fundamento de lo que se considerará como nudo central de la crítica hacia el historicismo. Específicamente, la categoría de irracionalidad en relación con aquellas teorías sociales que conciben una transformación de la totalidad del sistema, la sustitución del sistema capitalista por un sistema postcapitalista. Esto se enmarca dentro de la racionalidad instrumental que dota de significado al cientificismo popperiano. Esta racionalidad instrumental se relaciona con el concepto de razón en identificación del progreso basado en una tecnificación de la vida y, por ello, el paradigma popperiano está unido al paradigma moderno de la racionalidad técnico científica. De esta forma, la filosofía popperiana en su crítica al historicismo cae en el error de criticarlo desde la razón tecno científica, lo que se asume como fetichismo.

Unido a esto, se plantea una ruptura con tal perspectiva de concebir al marxismo desde la irracionalidad, sin tampoco caer en el falso dualismo racional/irracional. En cambio, se toma en cuenta que el problema central es la interpretación del marxismo, ya que el cientificismo popperiano realiza una lectura en clave estalinista, y por lo tanto va a concebir un marxismo mecanicista y eurocéntrico, vinculado a la racionalidad tecno científica, lo que dotará de argumentos para una profunda crítica y concebir su impertinencia. A diferencia de esta situación, la interpretación que se realiza del marxismo es desde la ruptura que hiciera Marx con el eurocentrismo, y la apertura del marxismo hacia otras subjetividades políticas que acompañan a la centralidad del proletariado, como también el quiebre y separación de una lógica universal de la historia. Además de la comprensión de que la relación centro/periferia es que hace posible que el 
capitalismo se reproduzca como sistema de opresión. Frente a esta problemática, se construye la posibilidad de un marxismo descolonizado como crítica a la filosofía de la ciencia de Popper, y como proyecto emancipador.

Es aquí donde se resalta la estructura semi-colonial de América Latina, como región donde el capital imperialista está unido a la economía regional, determinándose de esta forma las necesidades materiales para la transformación de la estructura económica latinoamericana, y el problema del poder político. Ante ello, se ha manifestado en trabajos anteriores lo siguiente:

América Latina como país semi-colonial donde el capital imperialista cumple un papel central en la economía, atando de manos al capital nacional al mismo, limpide que el empresariado nacional sea quien pueda llevar adelante una política antiimperialista consecuente, y por ello recae la hegemonía del bloque subalterno en el proletariado y sus organizaciones. Pensar al marxismo latinoamericano desde esta posición significa que deba expresarse como una teoría que comprenda el papel de los sujetos sociales en la praxis transformadora de la realidad, así como también el peso de la estrategia en la lucha por el poder. (Sicerone, 2015b, párr. 32)

La crítica al historicismo de Popper no discute con estas tesis, porque tiene una visión del marxismo como expresión directa del totalitarismo estalinista, lo cual no expresa las aspiraciones de libertad y transformación de la cotidianeidad de las clases subalternas, liberando el tiempo de sujeción al capital, en tiempo de ocio y de libertad. Cuando Popper en su libro La sociedad abierta y sus enemigos crítica al totalitarismo, lo que está poniendo en discusión es la concepción platónica de una sociedad utópica, una sociedad cerrada donde cada sujeto tengo un papel pre-diseñado, unas ataduras a un ideal metafísico que fundara la razón de ser de ese agrupamiento social. Por ello, el marxismo des-colonizado apunta a romper con las perspectivas burocráticas y deterministas que han hecho de la experiencias de millones de personas, una cárcel a cielo abierto, proponiendo la muerte y el destierro para aquellos que no comulguen con la unidireccionalidad de las decisiones políticas importantes. 


\section{Referencias Bibliográficas}

Bauman, Z. (2002). Modernidad líquida. Argentina: Ediciones Fondo de Cultura Económica.

Bensaid, D. (2006). Clases, plebes, multitudes. Venezuela: Ediciones El Perro y la Rana.

Díaz, E. (1996). La ciencia y el imaginario social. Buenos Aires: Ediciones Biblos. Eiff, L. (2010). "Merleau-Ponty lector de Marx. La Praxis dialéctica como génesis de Sentido" A Parte Rei, revista de filosofía, № 67, 1-8.

Ferreira, J. (2010). Comunidad, indigenismo y marxismo. Un debate sobre la cuestión agraria y nacional-indígena en los Andes. Bolivia: ed. Palabra Obrera. Gómez, Ricardo P. (2005). “¿El capitalismo es insuperable?: crítica a la tesis del fin de la historia en la versión de Hayek-Popper”. Revista Herramienta, 9 (29), 89101.

Gramsci, A. (2012). "Selección de fragmentos de Gramsci sobre Estado y hegemonía", en. Sociología Política, Cátedra M. Thwaites Rey, Departamento de Ciencia Política de la Universidad de Buenos Aires.

Horkheimer, M. (1973). Critica de la razón instrumental. Buenos Aires: Ediciones Sur.

Kohan, N. (2009). Marx en su (Tercer) Mundo. Hacia un socialismo no colonizado. Venezuela: Ediciones El perro y la rana.

Lanz, R. (1998). La deriva posmoderna del sujeto. Para una semiótica del poder. Caracas: Ediciones Universidad Central de Venezuela, Consejo de Desarrollo Científico y Humanístico.

Lyotard, F. (1993). La condición posmoderna. Buenos Aires: Ediciones Planeta Agostini.

Marx y Engels. (2000). El manifiesto comunista. Madrid: Ediciones Fundación Federico Engels.

Popper, K. (1980). La lógica de la investigación científica. Madrid: Ediciones. Tecnos

Popper, K. (1991). Conjeturas y refutaciones. Barcelona: Ediciones Paidos.

Popper, K. (1987). La miseria del historicismo. Madrid: Ediciones Alianza Editorial. 
Popper, K. (2010). La sociedad abierta y sus enemigos. España, Ediciones Paidos.

Restrepo, E., Rojas, A. (2010). Inflexión decolonial: fuentes, conceptos y cuestionamientos. Colombia: Ediciones Universidad del Cauca, Instituto de Estudios Sociales y Culturales Pensar, Maestria de Estudios Culturales, Universidad Javeriana

Sarmiento, D. (1993). Facundo: civilización o barbarie. Caracas: Ediciones Biblioteca Ayacucho.

Sicerone, D. (2015A) Una lectura gramsciana del marxismo latinoamericano", Pacarina del Sur [En línea], año 6, núm. 22, enero-marzo. Recuperado de http://www.pacarinadelsur.com/home/abordajes-y-contiendas/1077-una-lectura-

\section{gramsciana-del-marxismo-latinoamericano.}

Sicerone, D. (2015B). "Guerra de posiciones y de maniobra en América Latina, entre occidente y oriente. La estrategia de la revolución", Pacarina del Sur [En línea], año 6, núm. 24, julio-septiembre, 2015. Recuperado de http://www.pacarinadelsur.com/home/abordajes-y-contiendas/1178-guerra-de-posicionesy-de-maniobra-en-america-latina-entre-occidente-y-oriente-la-estrategia-de-la-revolucion Trotsky, L. (1975). Lecciones de octubre. ¿Qué fue la revolución rusa? Buenos Aires: Ediciones El Yunque.

Trotsky, L. (2010). "Sobre las tesis sudafricanas" en Comunidad, indigenismo y marxismo. Un debate sobre la cuestión agraria y nacional-indígena en los Andes. Ferreira (Autor). Bolivia, ed. Palabra Obrera. 